\title{
ARTÍ́CULOS
}

\section{El manejo de las escalas como obstáculo epistemológico en la divulgación de la nanociencia}

\author{
M.Carmen Sánchez-Mora* y Julia Tagüeña Parga**
}

RESUMEN: El presente trabajo parte de tres ideas, la primera es la noción de obstáculos epistemológicos (OE), explicaciones del mundo que, de acuerdo con Bachelard, limitan la comprensión de los conocimientos científicos durante su enseñanza. La segunda es que la nanociencia y la nanotecnología se han convertido en aspectos comunes de la vida diaria a los que debería tenerse acceso, pero donde suponemos que la percepción de las escalas nano funciona como OE para la comprensión de sus alcances y aplicaciones. Por último, consideramos que en los ambientes de aprendizaje informal de los museos de ciencias, dada la naturaleza de la interacción del público con sus exhibiciones, es posible detectar dichos OE. En este trabajo, se presenta un estudio empírico que lleva a una propuesta para trabajar los $\mathrm{OE}$ que representan las escalas nano.

PALABRAS Clave: nanociencia, nanotecnología, obstáculo epistemológico, museología de la ciencia, escalas nano.

ABSTRACT: This paper considers three main ideas. First, the notion of epistemological obstacle (EO) proposed by Bachelard, which considers that during science teaching, the learners have their own personal explanations about the world, that function as real epistemological obstacles (EO). These EO impair the understanding of scientific knowledge. The second one is that nanoscience and nanotechnology are becoming common aspects of daily life, but where the perception of nanoscales functions as real EO that interferes with is comprehension. And third, it is considered that in informal science education environments such as science museums, it is possible to detect those EO, due to the nature of the interaction between the visitors and the exhibits. In this paper an empirical research is presented, aiming to set a proposal to work with the EO represented by nanoscales.

KEY WORDS: nanoscience, nanotechnology, epistemological obstacle, science museology, nano scales.

\section{INTRODUCCIÓN}

Desde hace tiempo, en aras de mejorar la comunicación, se sugiere que en la divulgación que se realiza en los museos de ciencia (Scriven, 1983) se tomen en cuenta las representaciones del mundo que tiene el público potencial. Se trata de una tarea complicada, porque implica conocer las representaciones que tienen los visitantes sobre un tema en particular, y que han sido generadas y transmitidas por la propia sociedad. Dichas representaciones se han convertido en una especie de convenciones sociales o

\footnotetext{
* Dirección General de Divulgación de la Ciencia, Universidad Nacional Autónoma de México. <csanchezmora@hotmail.com>.

** Física de la Facultad de Ciencias de la UNAM y doctora en física del estado sólido por la Universidad de Oxford. Es investigadora del Centro en Investigación en Energía <www.cie.unam.mx> de la UNAM e investigadora nacional nivel III. Formó parte del equipo creador de Universum, museo de las ciencias de la UNAM. Actualmente, es la presidenta de la Sociedad Mexicana para la Divulgación de la Ciencia y la Técnica $<$ www. somedicyt.org.mx>.<jtp@cie.unam.mx>.
} 
personales que es necesario que el museo aborde o cuando menos cuestione a través de sus exhibiciones, si pretende divulgar el conocimiento científico de manera duradera y creíble por parte del público. Para ello, es necesario que conozca de antemano estas representaciones cuando planea y elabora sus exhibiciones.

En la divulgación de temas novedosos e imprescindibles como es la nanociencia, el divulgador museólogo se enfrenta no sólo a las representaciones que los visitantes puedan haberse formado del tema, sino también a la complejidad de los conceptos a exhibir, pero, sobre todo, a la exposición de un tema fuera del alcance sensorial del ser humano, asunto que complica aún más su comunicación (Crone, 2006).

La nanociencia no es en sí una nueva ciencia, se trata de la mecánica cuántica, el gran avance de principios del siglo XX, que describe el comportamiento de los átomos y fenómenos lejos de nuestra experiencia cotidiana.

En cambio, el término nanotecnología sí es actual y está relacionado con la aplicación de la nanociencia en la construcción, entre otros, de máquinas, brazos robóticos o motores más diminutos que una célula en la escala de 10 a $100 \mathrm{~nm}$. Hoy, la palabra abarca cualquier tecnología a escala nanométrica y aunque cada vez el público escucha más acerca de estos temas, difícilmente los comprende (Sánchez-Mora, 2006).

Para el caso de la nanociencia, nos enfrentamos a un cuerpo de conocimientos donde su manejo presupone obstáculos de orden conceptual, que en buena medida impiden que de acuerdo con el modelo canónico de la comunicación científica, se acorte la brecha entre el científico y la audiencia no científica (Bucchi, 1996), ya que ni siquiera los conocimientos utilizados pueden ser conceptualizados por proyecciones metafóricas a partir de las experiencias corporales, como lo hipotetiza Lackoff (1987, citado por Goatly, 1991: 41).

\section{El concepto de obstáculo epistemológico}

El concepto de obstáculo epistemológico (OE) ocupa un lugar muy importante en la teoría de Gastón Bachelard (1884-1962) (Bachelard, 1994), mismo que ha tenido un fuerte impacto en la filosofía de la ciencia y particularmente en su enseñanza. Este concepto empieza también a cobrar relevancia en los museos de ciencia, pues se ha visto que al servir de base para la construcción de exhibiciones, permite que el visitante se enfrente a dichos obstáculos y en ocasiones los cuestione, gracias a la posibilidad que tiene de interactuar con los equipos del museo (Hein, 1998). Una de las mayores aportaciones de los museos de ciencia a su enseñanza es que sus equipos permiten a los investigadores educativos estudiar cómo se comprenden diferentes temas científicos a partir del conocimiento de los modelos y esquemas, a través de los cuales los visitantes se explican el mundo (Haste, 1997).

Bachelard concibe el conocimiento más allá de una simple representación del mundo por parte del sujeto, a quien mira como un auténtico constructor de conocimiento.

De este modo, Bachelard se interesa por determinar cuáles son las condiciones que favorecen la conformación de una mente constructora de conocimiento científico. En su obra La construcción del espíritu científico se refiere al tema de los obstáculos epitemológicos:

Cuando se investigan las condiciones psicológicas del progreso de la ciencia, se llega muy pronto a la convicción de que hay que plantear el problema del conocimiento científico en términos de obstáculos. (Bacheland, 1994: 9) 
Este asunto de los obstáculos es central para Bachelard, pues los considera esenciales en el acto de conocer, así, postula que constituyen una herramienta conceptual a través de la cual, es posible comprender las causas de las dificultades y de los retrocesos en la construcción del conocimiento científico.

Bachelard opone esta noción a la idea operante a fines del siglo XIX de que existe una unidad de la experiencia o del conocimiento, predominante tanto en los empiristas como en los idealistas. La influencia del positivismo en el campo de las ciencias naturales acentuó el polo en el que las dimensiones cuantitativas primaron como fundamento y prueba, y sirvieron para sustentar la continuidad entre el conocimiento común y el científico. Se trataba de pensar, medir y contar y, desconfiar de lo abstracto. Había que atenerse a lo concreto. Este principio era fundamental para el científico que construía el nuevo conocimiento y para el docente que debería orientar el aprendizaje de ese conocimiento. Bachelard escribe que "ver para comprender" era el principio de dicha pedagogía, desde donde inicia un camino de enfrentamiento ante esa concepción de la ciencia y la pedagogía centrada en lo concreto.

Bachelard habla de que ya en la primera mitad del siglo XX se habían producido cambios en esa manera de concebir la ciencia, sobre todo, cuando la física comienza a hablar de cosas que no forman parte del pensamiento cotidiano; por ejemplo, el átomo y sus abstracciones teóricas se alejan del sentido común e incuso lo contradicen.

Para Bachelard, el obstáculo epistemológico es lo que se sabe y genera una inercia que dificulta el proceso de construcción de un saber nuevo. Considera que el científico y el público nunca parten de un conocimiento cero, viven en un contexto cultural de donde se desprenden sus conceptos y teorías. Cuando se enfrentan a una nueva concepción, ambos tienen una opinión de los asuntos científicos antes de entrar en contacto con ellos o después de aprender una teoría. Conocimiento vulgar, creencia u opinión encuentran en su origen diversos componentes de naturaleza social e individual, de allí la resistencia a desprenderse de ellos y a sustituirlos por otros.

Bachelard se instala en una ruptura con el sentido común; considera que el enemigo del conocimiento científico es la opinión, a la que mira como el primer obstáculo a vencer.

La relación entre el conocimiento científico y el conocimiento cotidiano o del sentido común es central en la obra de Bachelard, incluso, se enfrenta a lo que llama los "continuistas de la cultura", quienes creen que puede haber una continuidad entre el conocimiento común y el científico.

De acuerdo con lo anterior, poner al alcance del público los conocimientos de la ciencia exige penetrar en las concepciones del mundo que éste tiene, e intentar comprender sus modelos mentales para contrastarlos con otras explicaciones. Se trata de un empresa complicada, si se considera lo difícil que es que el visitante se desprenda de sus modelos mentales, sobre todo cuando se enfrenta cada día a una mayor diversidad en cuanto a las calidades y profundidades de los ambientes de aprendizaje a los que está expuesto.

Los educadores en general y los divulgadores en particular conocen el peligro que entraña el tratar de transportar los conocimientos de un medio a otro, por ejemplo, del formal al informal, pues los obstáculos pueden acentuarse e, incluso, hacerse más resistentes a la negociación. Los divulgadores tenemos claro que el espacio cultural es determinante del contenido que se construye, porque todos los aprendizajes son contextuales, y, que las representaciones están mediadas por el contexto en el que fueron construidas, y, a su vez, los contextos lo están por las representaciones. 
Consideramos que en los ambientes informales como los museos, los objetos de exposición, a causa del impacto emocional que producen o de las estrategias interactivas que proponen, pueden colocar a los visitantes en situación de revisar sus concepciones y en particular de cuestionar algunos de sus obstáculos y que este tipo de situación puede producirse cuando los constructores de exposiciones conocen a su vez tales obstáculos.

En este trabajo se plantea el uso de la evaluación formativa para la localización de obstáculos epistemológicos en la divulgación de la nanociencia y la nanotecnología.

\section{Los equipos museológicos}

Desde hace mucho tiempo se ha estudiado en el ámbito escolar la importancia que tienen los obstáculos para la construcción de conocimientos (Benlloch, 2002; Weissmann, 1997; Arca et al., 1997). En cambio, en el terreno de la museología de las ciencias, es decir, en la educación informal, se tienen pocas investigaciones al respecto. En los museos, espacios educativos informales donde impera la libre elección, cada visitante conduce su aprendizaje a diferentes ritmos y de acuerdo con sus necesidades y contextos. En gran parte el éxito de las exposiciones en cuanto al aprendizaje informal está en la capacidad que tiene el equipo expuesto para tomar en consideración en su diseño las concepciones de los visitantes (Gerber et al. 2001).

Hoy en día los equipos de los museos de ciencias están siendo diseñados a partir de la idea de que cada visitante construye su propio saber a partir de los elementos nuevos que asocia a los que ya posee. También sus diseños se han basado en el conocimiento de las preconcepciones, a fin de elaborar equipos que las modifiquen o al menos las cuestionen, objetivo que se logra creando situaciones llamadas de interactividad, descriptor complejo de una nueva forma de aprendizaje, donde son importantes el contexto, las acciones físicas, las características personales del aprendiz, y la posibilidad de entablar un conversación con otros visitantes que a su vez acuden al museo con sus propios conocimientos, intereses y motivaciones. Es finalmente esta conversación, la que actuará como un detonador de las ideas ingenuas y quizá de su cuestionamiento (Falk, 2002). Algunas investigaciones han demostrado que las exhibiciones, ya sea por el impacto emocional que causan, o por las estrategias interactivas que proponen, pueden colocar a los visitantes en situación de cuestionar sus concepciones y hasta de hacerlas tambalear (Sánchez-Mora, 2006).

El objeto de este trabajo es mostrar que el procedimiento de creación de una exposición puede apoyarse en el conocimiento y el análisis de los obstáculos epistemológicos, a fin de promover situaciones activas de descubrimiento para el público. Lo que se quiere señalar es el interés de reunir previamente información que permita conocer las concepciones del público, así como privilegiar en cada caso, soluciones museográficas que los inciten a la actividad sin reforzar los obstáculos ni crear otros nuevos. Estas situaciones, centradas en los aspectos que constituyen un obstáculo, pueden contribuir a hacer evolucionar las concepciones de los visitantes sobre los temas expuestos.

\section{Aportaciones de la enseñanza de la ciencia a la museografía científica}

Desde hace ya varias décadas (Arca et al., 1997; Benlloch, 2002; Hein, 1998; Weissmann, 1997), la investigación en didáctica de las ciencias señala que la educación científica 
supone una participación activa del sujeto en el descubrimiento y en la aplicación del saber. Existen numerosos estudios que muestran que este saber no es accesible si no se toma en cuenta ese aspecto. Hasta muy recientemente se empieza a considerar esta participación activa en la museología de la ciencia, que hasta hace poco tiempo solía estar en manos de museógrafos, arquitectos y científicos (Triquet, 1993).

El reto hoy en día es construir un museo constructivista enfocado en el visitante y no en el tema a exhibir, y donde se tome en cuenta que no hay conocimiento independiente del significado construido por el público. Algunos autores (Hein, 1998) proponen buscar en lo exhibido en el museo conexiones con lo familiar, es decir, lograr que el visitante pueda asociar la situación educativa con lo que ya conoce, atributo fundamental de cualquier posición constructivista. En opinión de Hein (1998), no sólo es difícil sino es casi imposible aprender algo sin poder hacer asociaciones con categorías familiares.

La divulgación de la nanociencia en los museos presupone entonces una dificultad extra que consiste en que el visitante haga asociaciones en un campo fuera de su alcance sensorial.

Una forma de abordar este problema es volver a Bachelard, cuando señala que tanto en el que aprende como en el investigador, el pensamiento científico progresa de manera dialéctica en virtud de revisiones sucesivas (Bachelard, 1994), lo que implica poner constantemente en tela de juicio las concepciones personales.

Numerosos estudios (Benlloch, 2002) han comprobado la importancia de tomar en cuenta las concepciones de los aprendices. Habrá que recordar que niños y legos interpretan los fenómenos a partir de su marco de referencia, pero que estas ideas no son infinitas y, por tanto, pueden agruparse en tipos. El aprendizaje depende de esas ideas, ya que el que aprende interpreta las nuevas informaciones a través de ellas. Si no se tiene esto en cuenta, el nuevo saber queda aislado del anterior y no logra modificarse o al menos hacerlo coexistir. Además, algunas ideas funcionan como verdaderos obstáculos para el aprendizaje, por lo que el conocimiento de ellas puede llevar a estrategias tanto de enseñanza como de divulgación más eficaces.

La mayoría de los estudios antes mencionados ocurren en el ambiente educativo formal, pero aun cuando no corresponden al ambiente informal de los museos, ciertas experiencias no dependen del lugar donde se desarrollen y parecen poder transportarse de un ámbito a otro según ya lo había demostrado Giordan en 1988.

El problema en el museo es que se trata de un ambiente de educación informal donde resulta imposible hacer un trabajo continuo con el receptor como ocurre en la escuela, lo cual no impide que las concepciones del público se utilicen como un punto de partida que permita seleccionar y diseñar los elementos a exhibir (Borun, 1993).

En la década de los años setenta del siglo XX, mientras se empezaba a cuestionar el papel educativo de los museos, también comenzaron a ver la luz estudios sobre la recepción de las exposiciones.

Scriven (1883) ya había señalado que quien construye el equipo requiere ante todo plantearse los objetivos de ésta y, enseguida, intentar conocer al público meta, momento en el que entran en juego sus concepciones sobre el tema que se pretende exhibir. Este momento es crucial para Scriven, porque incluso el museo puede funcionar como reforzador de estas falsas ideas. Por ello es que las evaluaciones inicial y formativa constituyen metodologías básicas e indispensables en el desarrollo de exhibiciones en los museos que se preocupan, si no por transformar las ideas ingenuas 
de los visitantes, por lo menos por hacerles cuestionar aquéllas con las que inherentemente acuden al museo (Taylor, 1998).

\section{LA EDUCACIÓN INFORMAL EN NANOCIENCIA}

Los avances en nanociencia, nanoingeniería y nanotecnología están revolucionando la medicina, la computación, la ciencia de materiales, la producción de energía y la manufactura; pero para el público general, estos avances son difíciles de comprender (Scheufele, 2005).

La investigación a nanoescala ha planteado un gran reto a las comunidades de educadores y comunicadores en la creación de nuevos métodos y aproximaciones que comuniquen o den a conocer el trabajo de los nanocientíficos e informen al público acerca de los avances en la investigación científica en este campo. También se considera muy importante la divulgación adecuada de estos temas, para capturar a las nuevas generaciones que podrían elegir carreras dentro de la nanociencia y nanotecnología (Crone, 2006).

Quizá una de las principales razones para buscar tener un público informado en estos asuntos es que se considera que la nanociencia y sus cada vez más abundantes y cotidianas aplicaciones deberían pasar a formar parte de la cultura de un público, en el que por un lado se requiere que comprenda los procedimientos científicos y los alcances en este campo y que, por otro lado, cuente con un vocabulario de términos relacionados con el mismo. En algunos países se busca también la comprensión de la nanociencia y la nanotecnología para el patrocinio económico de los proyectos científicos (Baindridge, 2002). Es importante mencionar también que toda nueva tecnología tiene implicaciones éticas que deben de ser consideradas y para que la sociedad participe en este debate debe estar bien informada (Bennet-Woods, 2008).

Las propiedades de los materiales al nivel nanométrico tienen ya varios usos y en el futuro cercano se prevé que haya muchas más aplicaciones potenciales como por ejemplo: filtros, es decir, membranas nanoporosas que serían el sustituto avanzado de los métodos actuales para eliminar contaminantes en líquidos o en el aire, o bien en otros dispositivos como memorresistores, biosensores, bioandamios, nanocápsulas, anticuerpos artificiales, celdas solares, celdas de combustible y nanotubos de carbono, entre otros. Estos últimos servirán para fabricar láseres más potentes, microchips más diminutos así como nuevos materiales superconductores.

\section{El conocimiento público de la nanociencia}

Los avances en la investigación a nanoescala plantean un gran reto a las comunidades de educadores y comunicadores, en tanto deberán crear nuevos métodos y materiales educativos que transmitan el trabajo científico y tecnológico en este campo. Esto incluye la adquisición de un vocabulario de términos relacionados con el nanomundo, y el acercamiento a un tema científico que se vuelve parte importante de nuestra vida diaria; de manera que la nanociencia y la nanotecnología deberían abordarse desde los programas escolares, hasta los sistemas de educación informal y los medios de comunicación.

En los últimos años se insiste (Scheufele y Lewenstein, 2005) en que la nanotecnología tiene incluso el potencial de revolucionar muchos aspectos de nuestra sociedad, dado que los avances en este campo están afectando nuestras vidas. Lo anterior 
hace ver este campo científico y tecnológico como un gran reto y al mismo tiempo como una gran oportunidad. Sin embargo, sus avances, métodos y alcances, permanecen invisibles y difíciles de comprender por el público general, de manera que, para informarle eficazmente acerca de la nanotecnología, se requiere lograr ante todo su comprensión, mediante un camino de comunicación más fluido con los científicos (Stevens et al., 2002).

En general, la percepción de la nanotecnología es positiva por parte de los científicos (Bainbridge, 2002), pero una vez que uno se acerca al público general, se entera de que sólo el $40 \%$ había escuchado de ella y menos de ese $40 \%$ la logran definir. De estos resultados se desprende que, si bien entre los investigadores en nanociencia hay una buena comunicación entre pares, para el público general, entre quienes están los posibles consumidores de los productos generados, hay una completa falta de comunicación con los generadores de la nanotecnología.

Aún sin comprenderla, los pocos que han oído hablar de nanotecnología tienen una opinión positiva o neutral acerca de ella. Esta percepción recabada en los EUA, se debe muy probablemente a que en general la gente le apuesta a la tecnología para mejorar sus vidas (Crone, 2006).

Pero cuando las evaluaciones y encuestas se refieren a los conceptos de la ciencia, la comprensión por parte del público es muy pobre, lo cual muestra que la escasa cultura científica sigue siendo un gran problema en general y, en especial, en relación con el tema de la nanociencia. Las explicaciones a esta circunstancia provienen de acuerdo con Crone (2006), a la baja comprensión del concepto de átomo y molécula, aspecto que convierte en incomprensible el lenguaje utilizado por los nanotecnólogos.

Una revisión de la literatura realizada también por Crone (2006) acerca del tema nos muestra que:

- El público no maneja conceptos como átomo y molécula y, por lo mismo, carece del conocimiento de la estructura atómica.

- Incorrectamente razona que los átomos y moléculas en una sustancia tienen las mismas propiedades que dicha sustancia tiene en la macroescala.

- Consideran a la materia como algo continuo, en lugar de formado por partículas.

- Y, sobre todo, tiene grandes dificultades para comprender las escalas invisibles al ojo humano.

Todo esto muestra que la apropiación de la nanotecnología por el público no es fácil, dado que implica la superación de varios obstáculos epistemológicos.

\section{La nanotecnología en los museos}

Si la divulgación de la nanociencia y la nanotecnología a través de cualquier medio se mira compleja porque implica la comunicación de una gran cantidad de conceptos no manejados por el público, pero necesarios para su comprensión, los retos impuestos por la nanociencia y la nanotecnología para su divulgación en los museos de ciencia son aún mayores, puesto que por su forma de comunicación, a través de exhibiciones, es necesario enfrentar a los visitantes a un tema cuya escala está fuera de la experiencia sensorial humana. Aún así, al ser los museos un medio de divulgación que permite comunicarse en simultáneo con amplias audiencias, se miran como uno de los sitios idóneos para lograrlo. Por otro lado, los museos de ciencia han logrado desarrollar la capacidad de hacer comprensibles fenómenos complejos (Taylor, 1998). 
Aunque Crone (2006) está consciente de las dificultades que implica la divulgación de la nanociencia, considera que es un tema que, por sus grandes implicaciones, debiera mostrarse a las grandes audiencias que concurren en los museos de ciencias. Percibe a éstos como el medio ideal para ayudar a los visitantes a introducirse en los fenómenos a nanoescala, en el entendido de que, para hacerlo, habrá que partir de investigación educativa en el ambiente informal.

\section{LA ESCALA NO VISIBLE COMO OBSTÁCULO EPISTEMOLÓGICO}

Sin ignorar las múltiples dificultades conceptuales que implica la enseñanza y la divulgación de la nanotecnología mencionadas en el apartado anterior, en este trabajo se procede bajo la hipótesis de que precisamente el tema de la escala no visible al ojo humano desnudo constituye el primer obstáculo epistemológico (Bachelard, 1994) para la comprensión de estas temáticas.

Consideramos, además, que este obstáculo es primario ya que a él subyacen las dificultades de la comprensión de la estructura atómica (por lo menos en el aspecto de la escala) y de la continuidad de la materia. De manera que - pensamos - en la medida en que se supere o aclare dicho obstáculo, se facilitará la introducción del público al tema de la nanociencia.

Tomando en cuenta las ventajas que ofrecen las exhibiciones museográficas para el acercamiento del público a conceptos difíciles, pero sin ignorar los serios peligros conceptuales que éstas pueden generar si no se diseñan de acuerdo con investigación educativa seria, es que en este trabajo ofrecemos una investigación llevada a cabo para estudiar las formas óptimas de presentación de las escalas no detectables por el ojo humano, con la intención de servir como base para el desarrollo de una exhibición más extensa acerca de la nanotecnología. Consideramos que si bien el tema puede exhibirse solamente mostrando objetos elaborados con base en la nanotecnología (como muchos museos de ciencia lo abordan), creemos que mientras los visitantes no comprendan el intervalo de medidas en las que se mueve la nanotecnología, la exhibición de estos objetos nanotecnológicos no pasará de ser una simple muestra en la que, sin la comprensión por parte del público, su capacidad educativa y formadora de opiniones será muy limitada.

Aprovechando la existencia en el museo Universum de la UNAM de una exposición sobre mecánica cuántica, en la cuál se muestra entre muchos otros equipos, una escala de medidas no visibles con el ojo desnudo, se realizó la evaluación formativa de la misma, con la intención de detectar los obstáculos que el público manifiesta para su interpretación y, con los resultados obtenidos, se plantea desarrollar una nueva propuesta museográfica que contemple el obstáculo epistemológico detectado en la primera.

\section{Una metodología adaptada a una exhibición}

Con apoyo de la problemática de la evaluación formativa y de la atención prestada a las ideas de quienes aprenden, desarrollamos y pusimos a prueba diversas situaciones que permiten hacer evolucionar de manera duradera las concepciones del público potencial que pueda acudir a un museo de ciencia. Si bien el proceso se desarrolló en realidad en un contexto diferente al del museo, es complementario de aquel y apunta a los mismos objetivos de construcción de saberes. Se eligió trabajar en el contexto 
escolar dada la facilidad que este ambiente nos ofrecía para controlar a los grupos, las interacciones y, sobre todo, la recolección de datos.

Hemos partido de la idea de que el creador de la exposición es el responsable de la elección de los conocimientos y de su organización, pero dicha creación puede regularse tomando en cuenta el punto de vista del visitante. Lo fundamental continúa siendo que la exposición interrogue, suscite la curiosidad, plantee problemas, motive al visitante a saber más, y lo impulse a consultar otros soportes como libros, Internet, etcétera.

Lo más importante no son sólo los mensajes, sino también la forma que se les da a los instrumentos de comunicación elegidas, desde la puesta en escena de los elementos, hasta el diseño de los objetos, pasando por las cédulas. Los visitantes perciben primero estos componentes y los agregarán a sus nuevos descubrimientos, por ello el museólogo emplea estrategias destinadas a crear situaciones de inducción que favorezcan la construcción del sentido por parte del público.

La investigación llevada a cabo en el ambiente formal y sus resultados, trasladados al ambiente informal, se basa en considerar las concepciones de los posibles visitantes, quienes descifrarán el objeto de exposición en función de sus propias concepciones que seguramente no son las del creador de la exposición y, particularmente, nos interesa saber si los elementos de la exposición constituyen obstáculos que el visitante puede transformar por completo en el sentido que se le propone. Es importante pues, que el creador de la exposición indague y tome en cuenta las concepciones generadas y los posibles obstáculos (Guichard, 1990), aspectos que dentro de la investigación en comunicación de la ciencia, permiten conocer mejor a la audiencia (Negrete y Lartigue 2010).

La realización de objetos de exposición no es en sí una investigación en didáctica, pero las indagaciones permiten informar a los museólogos sobre las concepciones de los visitantes. La transformación en objetos de los temas de la exposición es entonces un trabajo de creación, que puede apoyarse en los elementos descubiertos durante las investigaciones con el objeto de, más adelante, inventar situaciones problemáticas adaptadas.

\section{La evaluación diagnóstica}

En el terreno de la creación de exposiciones son de suma importancia los estudios empíricos que llevan a generar datos y mediciones en la comunicación de la ciencia, parte de lo cual se logra al indagar las relaciones que se dan entre las conductas observadas y el contexto museológico que las indujo. Por lo tanto, el plan de evaluación no estuvo completamente elaborado a priori, sino que evolucionó continuamente en función de las interacciones entre el evaluador, quien concibe la exposición, el público, y las limitaciones técnicas de los equipos interactivos.

Las hipótesis van surgiendo en el curso del estudio, de manera que sondeos y entrevistas construyen las metodologías esenciales de estas evaluaciones cualitativas (Taylor, 1998).

En los estudios que posteriormente se presentarán, se efectuaron pruebas previas y posteriores de naturaleza idéntica: cuestionarios orales sobre las propuestas gráficas presentadas y solicitud de respuestas escritas ante los cuestionamientos, todas ellas, para interpretar los resultados. En todo momento se suscitó una situación de in- 
tercambio de ideas, de las cuales las emitidas por los estudiantes que fungieron como visitantes potenciales al museo fueron registradas como "notas de campo".

Con el objeto de homogeneizar a la población estudiada y de poderla controlar, la evaluación diagnóstica se efectuó sobre el elemento expuesto en el museo pero dentro del ámbito del salón de clases. A esto se prestó la característica de la exhibición de tratarse de un gráfico ilustrado que podía trasladarse con toda facilidad al ámbito áulico.

\section{Metodología}

Con miras a detectar los obstáculos epistemológicos representados por la comprensión de la escala humana no visible y bajo la hipótesis de que éstos dificultan la comprensión de los conceptos básicos para entender la esfera de acción de la nanociencia y la nanotecnología, se llevó a cabo una evaluación formativa de un equipo de museo sobre nanoescalas. Cabe mencionar que dicho equipo ha sido anteriormente evaluado y resulta ser uno de los más atractivos de la sala de acuerdo con el criterio empleado corrientemente en los museos de ciencia, de contar el poder de atracción de los equipos por el número de visitantes que se acumulan en un cierto tiempo y el tiempo transcurrido frente a éstos (Hein, 1998). Sin embargo, dado que no posee referentes directos a la nanotecnología y sus estructuras, en lo que a las escalas se refiere, es que se retoma en este estudio como punto de partida de una evaluación formativa.

Esta evaluación formativa se desarrolló en un salón de clase de una escuela secundaria (36 estudiantes) a la que se trasladó el gráfico que constituye dicha exhibición (se proyectó). Una vez explicado el mismo, se procedió a plantear oralmente un cuestionario (que se anexa en la sección de resultados) con el cual se evaluó la comprensión de la escala propuesta y se detectaron los obstáculos principales que genera esta forma de presentación de las escalas no visibles. Cada vez que se planteaba una pregunta al grupo, se contaban el número de respuestas correctas. Habrá que añadir que la evaluación también incluyó las notas que se tomaron de las preguntas de los estudiantes; sin embargo, se omitió la filmación para no influir sobre la conducta del grupo.

A manera de comparación, con otro grupo (36 estudiantes) se explicó otra forma de presentar las escalas (propuesta didáctica) (Sánchez-Mora, 2000). Esta forma de presentación consiste en hacer comparaciones macroscópicas con el mundo visible, en el entendido de que la traducción a las "escalas del mundo visible", facilitarán la comprensión del concepto de la nanoescala. Igualmente, se presentaron las escalas y los ejemplos a todo el grupo, se contestaron dudas y se trabajó con algunos ejemplos, muy semejantes éstos, mismos que después se utilizaron en la evaluación. Hay que hacer notar que aunque se procuró que las preguntas aplicadas en los tres diferentes eventos de evaluación fueran similares, la naturaleza de los materiales expuestos implicó hacer pequeños ajustes a los cuestionarios (mismos que se observan en la tabla). Una vez que los grupos manifestaron que ya no tenían más dudas sobre lo explicado, se procedió a transmitirles oralmente las 10 preguntas de prueba, y en cuanto todo el grupo manifestaba que ya había resuelto cada pregunta y que ya no añadiría nada más, se procedía a plantear la siguiente. El proceso de explicación de la tabla tomó 35 minutos para la gráfica del museo y 27 minutos para la propuesta didáctica; mientras que el proceso de examen se ajustó en ambos casos a 50 minutos, ya que se dieron cinco minutos por pregunta (en general, cada pregunta era resuelta por la totalidad del grupo en un promedio de cuatro minutos, salvo en una pregunta que les resultó muy difícil en la que hubo que dar un tiempo de seis minutos). Lo an- 
terior significa que el tiempo de trabajo con cada grupo fue de aproximadamente una hora y media. La parte más importante en cada prueba consistió en plantear tres preguntas de aplicación de las escalas relativas de tres estructuras nanotecnológicas ficticias, cuyo objetivo era corroborar la comprensión de las escalas a nivel nano. Estas preguntas corresponden a las tres últimas de cada cuestionario.

Una semana después de haber aplicado las dos primeras pruebas y de acuerdo con los resultados obtenidos, se procedió a plantear una tercera forma de presentación en la cual se intenta subsanar muchas de las dudas y los errores cometidos en la interpretación de las dos pruebas anteriores como son:

a) Los estudiantes requieren situarse dentro de una escala métrica en la que puedan visualizar las reducciones en tamaño a partir del milímetro (esto se logró pidiéndoles que observaran en su regla un milímetro y que imaginariamente lo fueran dividiendo cada vez en diez partes más pequeñas). En el anexo puede verse el gráfico que se utilizó para tal fin.

b) Los estudiantes requieren de un mismo ejemplo que vaya disminuyendo en escala, ya que en el segundo ejercicio se notó que la falta de referentes en los ejemplos mostrados generaba muchas confusiones (finalmente, quien nunca ha visto un paramecio, un virus o un eritrocito, tiene muchos problemas para comprender las escalas relativas). De acuerdo con lo anterior, es que se decidió presentar en la tercera modalidad tres ejemplos a escoger, uno de ellos consistió en ir "reduciendo" el tamaño desde un árbol, a una hoja, el grueso de la hoja, las células vegetales, la pared de estas células, las fibrillas de celulosa, las macro y microfibrillas, la molécula de glucosa y, finalmente, el átomo de carbono. En otro ejemplo, se mostró desde una jeringa, su aguja, la punta de ésta, las bacterias localizadas en dicha punta, los virus que caben en esa bacteria, el ARN viral, hasta un átomo de carbono. Finalmente, se utilizó un ejemplo de ir disminuyendo el tamaño dentro de una célula.

La propuesta gráfica de esta tercera modalidad se puede ver en el anexo.

Los tiempos de explicación y de resolución de las preguntas fueron semejantes a los de los dos primeros tratamientos.

Tanto en la modalidad didáctica, como en la derivada de la exhibición de museo y en la propuesta surgida del análisis de las dos anteriores, se solicitó a los alumnos la respuesta a las diez preguntas asentadas en la tabla. Cabe resaltar que la parte más importante de estos cuestionarios consiste en pedir a los sujetos experimentales que ubiquen la escala a la que se encuentran diferentes objetos nanotecnológicos como los nanomotores, nanotubos o nanomallas (que aparecen en las tres últimas preguntas para cada caso), y que en ningún momento se trabajó con el concepto de átomo ni de molécula para no entorpecer los resultados sobre la comprensión de las escalas. Sin embargo, tenemos claro que este trabajo deberá complementarse posteriormente con la indagación acerca de la comprensión del concepto de átomo y su estructura, así como de la naturaleza discontinua de la materia, sin los cuales la comprensión de la nanotecnología no puede estar completa.

Se trabajó con tres diferentes grupos, cada uno de 36 estudiantes de entre 12 y 14 años de edad, sobre la base de que sus conocimientos se asemejan a los del público general que acude al museo. 
Mundo Nano | Artículos | Vol. 4, No. 2, julio-diciembre, 2011 | www.mundonano.unam.mx

\section{Resultados}

Tabla comparativa de resultados de acuerdo con las preguntas

\begin{tabular}{|c|c|c|}
\hline Equipo del museo & Sugerencia didáctica & Presentación sugerida \\
\hline $\begin{array}{l}\text { ¿Cuál crees que sea el menor } \\
\text { tamaño de un objeto visible con el } \\
\text { ojo desnudo? } \\
2 / 36\end{array}$ & $\begin{array}{l}\text { ¿Cuál es el mayor objeto visible con } \\
\text { el ojo desnudo? } \\
35 / 36\end{array}$ & $\begin{array}{l}\text { ¿Cuál es el mayor objeto visible con } \\
\text { el ojo desnudo? } \\
35 / 36\end{array}$ \\
\hline $\begin{array}{l}\text { ¿Cuál es la medida de este objeto } \\
\text { en nanómetros? } \\
7 / 36\end{array}$ & $\begin{array}{l}\text { ¿Cuál es la medida de este objeto } \\
\text { en nanómetros? } \\
2 / 36\end{array}$ & $\begin{array}{l}\text { ¿Cuál es la medida de este objeto } \\
\text { en nanómetros? } \\
25 / 36\end{array}$ \\
\hline $\begin{array}{l}\text { ¿Cuál crees que sea el mayor objeto } \\
\text { visible con microscopio electrónico? } \\
0 / 36\end{array}$ & $\begin{array}{l}\text { ¿Cuál es el mayor objeto visible con } \\
\text { microscopio electrónico? } \\
30 / 36\end{array}$ & $\begin{array}{l}\text { ¿Cuál es el mayor objeto visible con } \\
\text { microscopio electrónico? } \\
33 / 36\end{array}$ \\
\hline $\begin{array}{l}\text { ¿Cuál es la medida de este objeto } \\
\text { en nanómetros? } \\
0 / 36\end{array}$ & $\begin{array}{l}\text { ¿Cuál es la medida de este objeto } \\
\text { en nanómetros? } \\
29 / 36\end{array}$ & $\begin{array}{l}\text { ¿Cuál es la medida de este objeto } \\
\text { en nanómetros? } \\
30 / 36\end{array}$ \\
\hline $\begin{array}{l}\text { ¿Cuál crees que sea el mayor objeto } \\
\text { visible con microscopio óptico? } \\
0 / 36\end{array}$ & $\begin{array}{l}\text { ¿Cuál es el mayor objeto visible con } \\
\text { microscopio óptico? } \\
29 / 36\end{array}$ & $\begin{array}{l}\text { ¿Cuál es el mayor objeto visible con } \\
\text { microscopio óptico? } \\
34 / 36\end{array}$ \\
\hline $\begin{array}{l}\text { ¿Cuál es la medida de este objeto } \\
\text { en nanómetros? } \\
0 / 36\end{array}$ & $\begin{array}{l}\text { ¿Cuál es la medida de este objeto } \\
\text { en nanómetros? } \\
2 / 36\end{array}$ & $\begin{array}{l}\text { ¿Cuál es la medida de este objeto } \\
\text { en nanómetros? } \\
33 / 36\end{array}$ \\
\hline $\begin{array}{l}\text { Si un virus mide } 100 \text { nanómetros, } \\
\text { ¿dónde lo colocarías en esta } \\
\text { escala? } \\
3 / 36\end{array}$ & $\begin{array}{l}\text { Si un virus mide } 100 \text { nanómetros, } \\
\text { ¿a qué medida equivaldría en esta } \\
\text { escala relativa de centímetros y } \\
\text { metros? } \\
16 / 36\end{array}$ & $\begin{array}{l}\text { Si un virus mide } 100 \text { nanómetros, } \\
\text { ¿cuántos cabrían lado a lado en un } \\
\text { milímetro de tu regla? } \\
19 / 36\end{array}$ \\
\hline $\begin{array}{l}\text { ¿Cuál es la medida máxima en } \\
\text { nanómetros que debe tener una } \\
\text { nanoestructura para entrar a una } \\
\text { célula? } \\
\text { o/36 }\end{array}$ & $\begin{array}{l}\text { ¿Cuál es la medida máxima en } \\
\text { nanómetros que debe tener una } \\
\text { nanoestructura para entrar en una } \\
\text { célula? } \\
21 / 36\end{array}$ & $\begin{array}{l}\text { ¿Cuál es la medida máxima en } \\
\text { nanómetros que debe tener una } \\
\text { nanoestructura para entrar a una } \\
\text { célula? } \\
29 / 36\end{array}$ \\
\hline $\begin{array}{l}\text { Si un nanomotor mide lo mismo } \\
\text { que una célula, ¿cuánto mide en } \\
\text { nanómetros? } \\
\text { 0/36 }\end{array}$ & $\begin{array}{l}\text { Si un nanomotor mide lo mismo } \\
\text { que una célula, ¿cuánto mide en la } \\
\text { escala relativa? } \\
12 / 36\end{array}$ & $\begin{array}{l}\text { Si un nanomotor mide lo mismo } \\
\text { que una mitocondria, ¿cuánto mide } \\
\text { en nanómetros? } \\
33 / 36\end{array}$ \\
\hline $\begin{array}{l}\text { ¿Con cuál de los objetos } \\
\text { nanotecnológicos aquí presentados } \\
\text { se podría modificar internamente } \\
\text { una bacteria? } \\
\text { 0/36 }\end{array}$ & $\begin{array}{l}\text { ¿Con cuál de los objetos } \\
\text { nanotecnológicos aquí presentados } \\
\text { se podría modificar internamente } \\
\text { una bacteria? } \\
7 / 36\end{array}$ & $\begin{array}{l}\text { ¿Con cuál de los objetos } \\
\text { nanotecnológicos aquí presentados } \\
\text { se podría modificar al ADN? } \\
30 / 36\end{array}$ \\
\hline
\end{tabular}


Con objeto de facilitar la lectura y el análisis de los resultados obtenidos en los tres tratamientos, éstos se han colocado en la misma tabla en la que se muestran las preguntas planteadas en cada uno de los tres casos. Y para su mejor comprensión, se han organizado los resultados para los tres tratamientos en la gráfica 1.

GRÁFICA 1. Porcentaje de respuestas correctas para los tres tratamientos

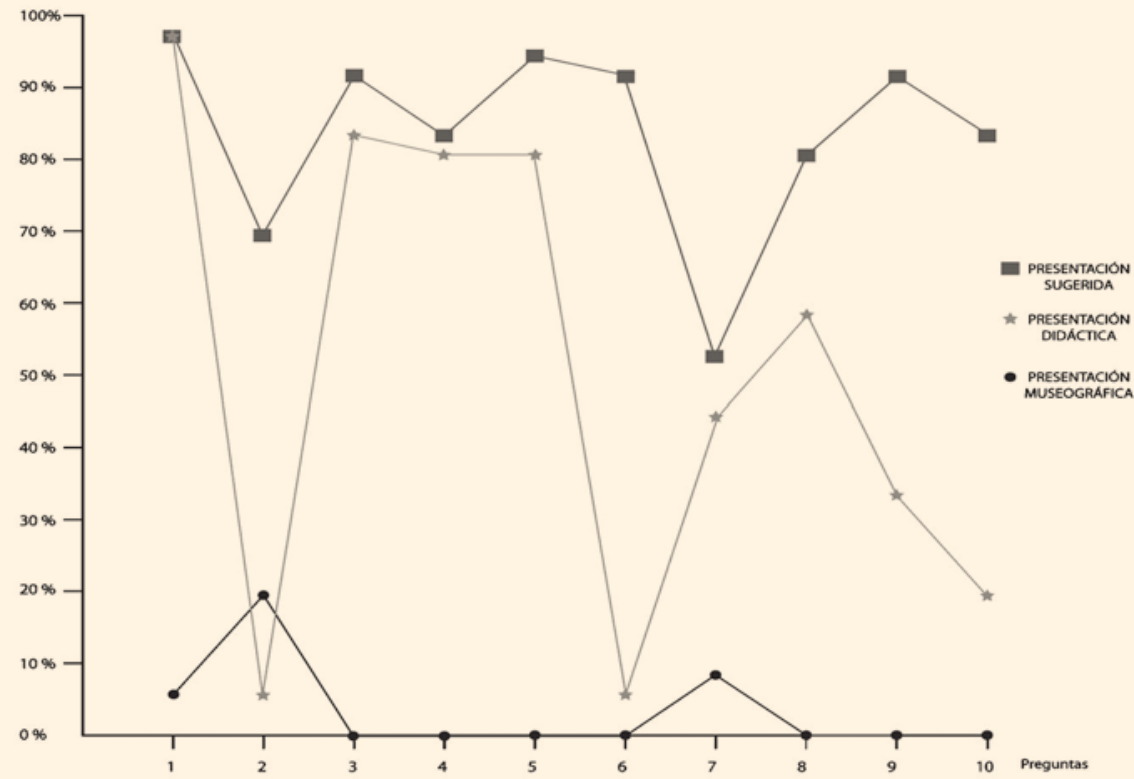

Fuente: Elaboración propia.

Como puede observarse, la lectura de la propuesta original (tabla proveniente del museo) presenta muchas dificultades para su lectura, lo que redundó en una enorme dificultad para que los estudiantes situaran las estructuras nanotecnológicas en la escala, lo anterior se concluye por la falta total de respuestas correctas (ver las tres últimas preguntas y sus respuestas). Todas las preguntas arrojaron los mismos resultados negativos, salvo aquella que es demasiado obvia como en la que se les pide que localicen a un virus de $100 \mathrm{~nm}$ en la escala, aún así, sólo tres estudiantes de 36 dieron una respuesta correcta.

Si se revisan los resultados de la propuesta didáctica (segunda columna), se encuentra una ganancia cognitiva absolutamente mayor que con la propuesta proveniente del museo, sin embargo, llama la atención que si bien hay un gran número de respuestas correctas (29/35) cuando se pregunta el tamaño del mayor objeto visible con un microscopio óptico, los estudiantes no pueden dar su medida en nanómetros y ni siquiera pueden trabajar con una escala relativa, como se puede ver en la pregunta número 7 (opción didáctica) en la que casi la mitad de los estudiantes fueron incapaces de responder correctamente.

En cuanto a la aplicación nanotecnológica en esta misma propuesta didáctica, observamos que, un número significativo de estudiantes puede responder adecuadamen- 
te la pregunta 8, lo cuál señala que comprenden que una nanoestructura de tamaño menor a una célula puede penetrar en ésta (las 14 respuestas incorrectas coincidieron en señalar $100 \mathrm{~nm}$ en lugar de 10,000 nm), pero que tienen dificultades con el manejo de las escalas. Lo que resulta notorio es que el manejo de las escalas relativas los confunde más, lo cual aparentemente genera un gran número de respuestas incorrectas en la última pregunta (7/35) en donde señalan que el nanomotor podría penetrar en una bacteria, en lugar de la nanoestructura, que es la respuesta correcta.

El análisis estadístico de los resultados anteriores señala que de la población estudiada (un total de 36 alumnos), se puede notar que existe una diferencia significativa entre las respuestas del cuestionario para los tres tratamientos (con un intervalo de confianza del $95 \%(\mathrm{p}<0.05)$ ). Esto se muestra en la gráfica 2, en donde para los tres grupos experimentales, se asientan los valores de sus medias para cada pregunta, conforme al sistema SPSS (Statistical Package Social Sciences) 11.5 para Windows. Se utilizó una comparación múltiple y el método de Fisher para discernir las menores diferencias, donde puede observarse cómo las medias entre cada grupo son muy diferentes entre sí.

Como se puede apreciar, para el grupo de equipo de museo, las preguntas $3,4,5$, $6,8,9$ y 10 , no muestran una diferencia significativa entre sus medias, ya que de los 36 estudiantes, ninguno respondió correctamente.

Respecto al grupo en el que se utilizó la sugerencia didáctica, y en el que se trabajó con la presentación sugerida, se puede afirmar que hay más comprensión en este

GRÁFICA 2. Gráfico de intervalo de confianza para la la media del grupo de preguntas

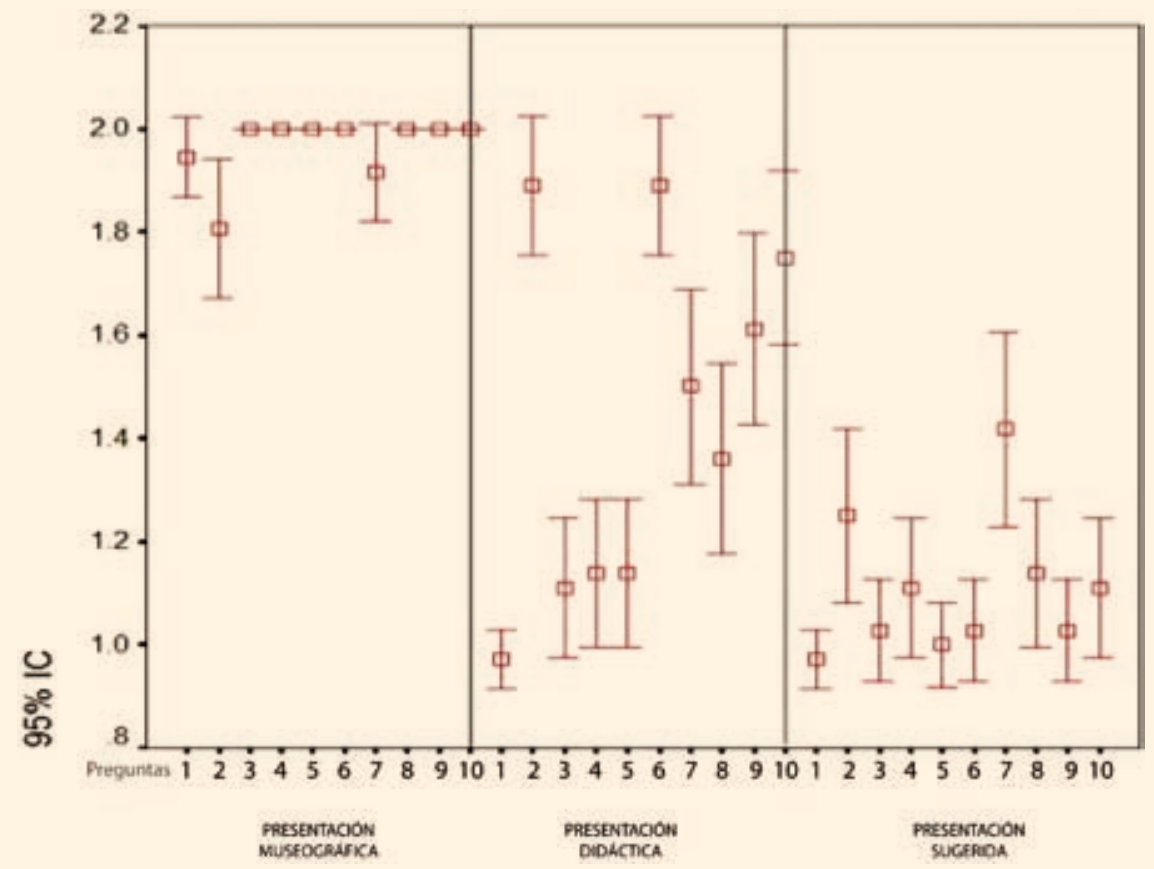

Fuente: Elaboración propia. 
último, ya que el análisis estadístico señala que sus medias en general están más cercanas al valor de $\mathrm{p}=0.05$.

La mayor diferencia significativa ocurre cuando se analiza la pregunta 6, sobre la medida de un cierto objeto en nanómetros (en este caso una bacteria). Esta diferencia se hace notable al comparar las medias entre grupos. Lo anterior significa que esta pregunta es mucho menos comprensible utilizando el equipo del museo, que cuando se resuelve con ayuda de la sugerencia didáctica y de la presentación sugerida, siendo esta última la que permite la mayor comprensión de todas (lo anterior se nota al revisar cómo la medida de la media tiende a acercarse más al valor de cero para ese caso).

A diferencia de lo anterior, cuando se pide a los estudiantes que indiquen ¿cuál es el menor objeto visible con el ojo desnudo? (pregunta 1), se encuentra que no hay una diferencia significativa entre las respuestas en los tratamientos Sugerencia didáctica y Presentación sugerida, pero que sí se aprecia una gran diferencia significativa cuando se utilizan estos dos métodos, y el denominado equipo de museo. Lo anterior señala que dicho equipo ni siquiera permite resolver un problema que resultó demasiado sencillo para los otros dos tratamientos.

Finalmente, si se comparan las medias de los tres últimos problemas, se verá la supremacía que tiene la presentación sugerida por sobre los otros dos tratamientos; puede decirse que éste último facilita no sólo la comprensión de los conceptos sino su aplicación a la resolución de problemas sencillos.

\section{DisCusión}

Como se había anunciado, la tercera prueba se derivaría de los obstáculos encontrados en la evaluación tanto de la propuesta didáctica como de la museográfica. Dichos obstáculos son:

a) El problema con las potencias de diez que resultan incomprensibles para los estudiantes y hacen que confundan los tamaños relativos, a pesar de que se les planteen problemas prácticamente resueltos, como decirles la medida de un virus y que lo sitúen en la tabla. Este problema se abordó en la nueva propuesta haciendo ver a los estudiantes que en cada nueva medida se va subdividiendo en diez partes iguales la precedente

b) El problema con la traducción a escalas visibles que promueve la propuesta didáctica, ya que los alumnos encuentran una gran dificultad en cambiar entre escalas, lo que les lleva a intentar una conversión de medidas entre la escala macroscópica y la microscópica, para la cual no están capacitados. Este problema se abordó en la nueva propuesta eliminando la conversión entre escalas al quitar la escala de referencia macro.

c) El problema de desconocimiento de los organismos microscópicos o de los compuestos presentados, ya que a una persona que ignora lo que es un paramecio o que nunca ha visto un virus o una bacteria, le cuesta mucho trabajo ubicarlos en una escala de tamaños. Este problema se abordó en la nueva propuesta de dos maneras: en una se plantearon tres diferentes ejemplos, intentando con ello buscar una gama mayor de organismos o estructuras que los estudiantes pudieran conocer o por lo menos haber escuchado. Otra solución 
fue llevar el mismo ejemplo de lo macro a lo nano, tales son los ejemplos del árbol a la molécula de carbono; de la aguja al ARN del virus y de la hidra al núcleo celular.

Los resultados obtenidos y que pueden observarse en la tercera columna de la tabla, señalan un aumento notorio en el número de aciertos respecto a los tratamientos anteriores. En general, las respuestas correctas están alrededor del $80 \%$ o más, y sobre todo, se presentan resultados correctos para las tres últimas preguntas a las cuales el grupo contestó con exclamaciones que denotaban la obviedad de las preguntas. Con este último tratamiento, sin embargo, se encontró que hubieron dos respuestas con menor puntaje, en una de ellas (la segunda) hubo confusión en el grupo, ya que se les permitió elegir el ejemplo que prefirieran (el árbol, la jeringa o la hidra) y, en particular, se encontraron problemas en aquélla acerca de colocar una hilera de virus de $100 \mathrm{~nm}$ de ancho en un milímetro, en la que casi la mitad del grupo respondió incorrectamente. Cuando se indagó el posible origen del error, se pudo notar que se trató de la interpretación de la instrucción y no de la falta de comprensión del concepto. Por tanto, se recomienda que en caso de transportar estas ideas a un nuevo equipo de museo, se sea muy explícito cuando se sugieran este tipo de ejercicios.

Como puede verse, la evaluación formativa constituye una poderosa arma para adecuar el mensaje de las exhibiciones a las respuestas y recepciones de los visitantes de los museos. En este caso, se ha hecho un complemento de este tipo de evaluación con la denominada inicial o formativa, en tanto se probaron otras formas de exhibir el difícil tema de la comprensión de las escalas fuera del alcance sensorial humano, mismas que son indispensables para abrir la puerta a la nanociencia y la nanotecnología.

Cabe aclarar que la tercera propuesta surgida a partir de la detección de los obstáculos epistemológicos para entender las nanoescalas, logró una comprensión sustantiva del tema, al punto que permitió la solución de un problema más complejo como es resolver el siguiente: Si un virus mide 100 nanómetros, ¿cuántos cabrían lado a lado en un milímetro de tu regla?, asunto que parecía muy difícil de resolver con las dos propuestas de exhibición didáctica y museográfica original.

Los resultados han mostrado la bondad de incluir las potencias de diez de manera simplificada, los ejemplos en un continuo de tamaños y con organismos conocidos por los visitantes, cuando se trata de hablar de escalas no visibles. Consideramos igualmente que toda exposición que muestre el tema de la nanotecnología deberá acercar al público en primera instancia a la superación de los obstáculos epistemológicos inherentes al tema y no sólo exhibir la nanotecnología a través de los productos comerciales o de investigación derivados de la nanociencia. A esto habrá que añadir exhibiciones que aclaren los tres restantes obstáculos reportados por la bibliografía (Crone, 2006), como son el concepto de átomo, su constitución, y la naturaleza discontinua de la materia.

Finalmente, los resultados muestran que concebir elementos de exposición basándose en el conocimiento de las concepciones del público y de los obstáculos epistemológicos, a menudo puede hacer evolucionar de manera duradera sus conocimientos. Esta demostración se opone a la idea tradicional según la cual el impacto que ejerce la museografía en el público corresponde solamente al orden de la sensibilización. Por el contrario, muestra que en ciertas condiciones, el museo también puede contribuir a desarrollar saberes y hacerlo incluso mejor que una enseñanza frontal formal y tradicional que no demanda reflexión por parte del receptor. 
Pero también es necesario señalar algunos límites de la exhibición, no es posible construir elementos estructurados durante una visita. Si bien ésta puede emocionar, despertar interrogantes, sorprender y por tanto dejar huellas en la memoria, sólo puede transmitir conocimientos fragmentarios. Posteriormente, la escuela deberá estructurar lo adquirido, pues el paso por una exposición no es suficiente para asentar aprendizajes que requieren procesos más largos y hasta repetitivos. No obstante, las herramientas museográficas interactivas construidas en estas condiciones pueden constituir ayudas para el aprendizaje del público que las visita como un simple entretenimiento.

Tenemos claro que éstas no sustituyen a las herramientas pedagógicas, pero que alimentan de manera eficaz la creatividad de quienes deciden los elementos de exposición y los ayuda a encontrara las soluciones técnicas que se apoyen en las dificultades de comprensión de su público.

\section{Conclusiones}

El conocimiento y abordaje de un primer obstáculo epistemológico para abordar el tema de la nanociencia, como es la comprensión de las escalas invisibles para el ojo humano, constituye una excelente puerta de entrada al umbral de esta importante rama de la ciencia que presenta ya un futuro prometedor y que debería ser del dominio público.

El análisis mostrado prueba que la creación de elementos de exposición puede basarse en la investigación educativa.

Reuniendo previamente informaciones que permitan tener una idea de los interrogantes y las concepciones de los visitantes, así como de los obstáculos que pudieran percibirse, creando prototipos y poniéndolos a prueba mediante pruebas, a fin de evitar reforzar ciertos obstáculos o crear otros nuevos mediante las modelizaciones propuestas, se puede dar prioridad a soluciones museográficas que inciten al visitante a participar activamente en la comprensión de temas complejos.

\section{BiBLIOgRAFía}

Arca, M., P. Guidoni y P. Mazzoli. (1997). Enseñar ciencia. Cómo empezar: reflexiones para una educación científica de base. Paidós Educador. Col. Rosa Sensat. México.

Bachelard, G. (1994). La formación del espíritu científico. Siglo XXI editores, 20ª. Edición. México.

Bainbridge, W. (2002). "Public attitudes toward nanotechnology". Journal of Nanoparticle Research, 4: 561-570.

Bennet-Woods, D. (2008). Nanotechnology: Ethics and society. CRS press Taylor and Francis Group, New York.

Benlloch, M. (comp.). (2002). La educación en ciencias: ideas para mejorar su práctica. Paidós, Ecuador.

Borun, M. (1993). "Naive knowledge and the design of science museum exhibits". Curator, 36, num. 3: 201:220.

Bucchi, M. (1996). "When scientists turn to the public: Alternative routes in science communication". Public Undersanting of Science, 5: 375-394. 
Crone, W. y S.E. Koch (ed.), (2006). Bringing nano to the public: A collaboration opportunity for researchers and museums. NISE Network. Science Museum of Minnesota, St.Paul, Minnesota.

Falk, J.H. (2002). “The contribution of free choice science learning to public understanding of science". Interciencia, 27, 62-65.

Gerber, B.L., Cavallo, A.M.L., y Marek, E.A. (2001). "Relationships among informal

environments, teaching procedures and scientific reasoning abilities". International Journal of Science Education, 23 (5), 535-549.

Giordan, A. (1997). Des idées pour apprendre. Niza, Z’Editions, 360 pp.

Goatly, A. (1997). The language of metaphors. Routledge, London, $360 \mathrm{pp}$.

Guichard, J. (1993). "La prise en compte du visiteur comme outil de la concepction muséologique". Publics et Musées, $3: 111-135$.

Haste, H. (1997). "Myths, monsters, and morality. Undestanding "antiscience" and the media message". Interdisciplinary Science Reviews, 22 (2): 114-120.

Hein, G. 1998. Learning in the museum. Routledge, London.

Negrete, A. y C. Lartigue. (2010). "The science of telling stories: Evaluating science communications via narratives (RIRC method)". Journal Media and Communication Studies, 2(4): 98-110.

Sánchez-Mora, C. y Herrera, C. (2000). "La enseñanza de las escalas invisibles”. Correo del Maestro, vol. 16, núm. 21: 27-32.

Sánchez-Mora, C. (2006). “La exposición museográfica como apoyo a la enseñanza

de la mecánica cuántica”. Revista Mexicana de Investigación Educativa, 11 (30), 913- 942.

Scheufele, D., y Lewenstein, B. (2005). "The public and nanotechnology: How citizens make sense of emerging technologies". Journal of Nanoparticle Research, 7: 659-667.

Scriven, C.G. 1983. "Evaluation and the exhibit design process: Pretesting audience as a design tool". Iconographie. 2; Danmark Mobilia Press.

Stevens, M.G., Owens C. y Wuhrer, R. (2002). "Nanotechnology in society”. Australian Science Teachers'Journal, 48:3: 22-27.

Taylor, S. (1998). Comment améliorer des éléments d'éxposition avec l'évaluation formative. OCIM, Dijon.

Triquet, E. (1993). Analyse de la genése d'une exposition. Tesis. Universidad Claude Bernard, Lyon. 384 pp.

Weissman, H. (comp.) (1997). Didáctica de las ciencias naturales, aportes y reflexiones. Paidós Educador. México. 


\section{ANEXO}

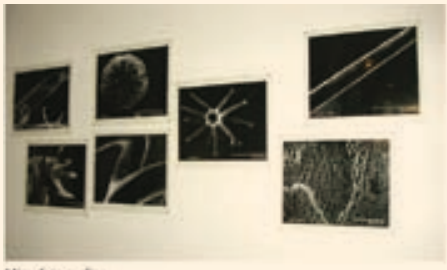

Uicuelonsogrtin:

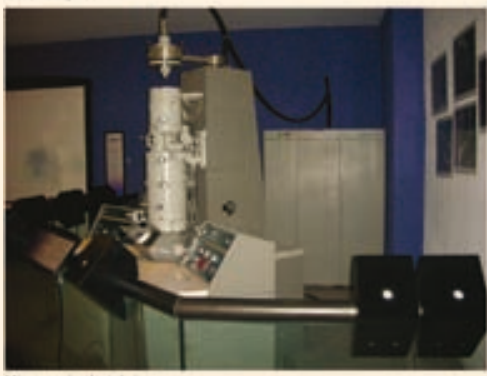

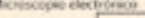
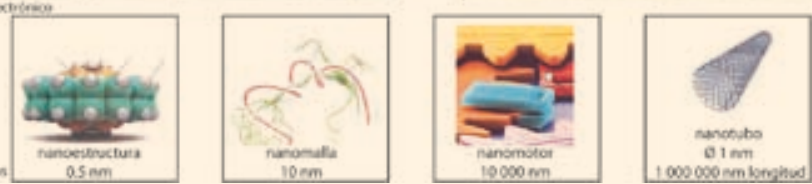

\begin{tabular}{|c|c|c|c|}
\hline & ESCALA REAL & $\begin{array}{l}\text { ORDEN DE } \\
\text { MAGNITUDD }\end{array}$ & $\begin{array}{l}\text { ESCALADE } \\
\text { REFERENCIA }\end{array}$ \\
\hline & \begin{tabular}{|c|}
\multicolumn{1}{c|}{$\mathrm{mm}$} \\
$1 \mathrm{milimetro}$ \\
$1000000 \mathrm{~nm}$
\end{tabular} & Piojo & 10 kilómetros \\
\hline $\begin{array}{l}\text { Limite de lo visible } \\
\text { con el ojo desnudo }\end{array}$ & $100000 \mathrm{~nm}$ & Paramecio & 1 kilometro \\
\hline & $10000 \mathrm{~nm}$ & Célula & 100 metros \\
\hline $\begin{array}{l}\text { Limite del } \\
\text { microscopio óptico }\end{array}$ & $\frac{\mu}{1 \mathrm{micra}}$ & Bacteria & 10 metros \\
\hline & 100 nanometros & Virus & 1 metro \\
\hline 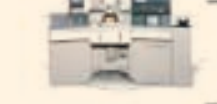 & 10 nanometros & $\begin{array}{l}\text { Macromolécul } \\
\text { Celulosa }\end{array}$ & 10 centimetros \\
\hline $\begin{array}{l}\text { Limite del } \\
\text { microscopio } \\
\text { electrónico }\end{array}$ & $\begin{array}{c}\mathrm{nm} \\
1 \text { nanometro }\end{array}$ & $\begin{array}{l}\text { Molécula } \\
\text { Glucosa }\end{array}$ & 1 centimetro \\
\hline & $\frac{\mathrm{A}}{\frac{1 \text { ANGSTROM }}{0.1 \mathrm{~nm}}}$ & Átomo & 1 milimetro \\
\hline
\end{tabular}




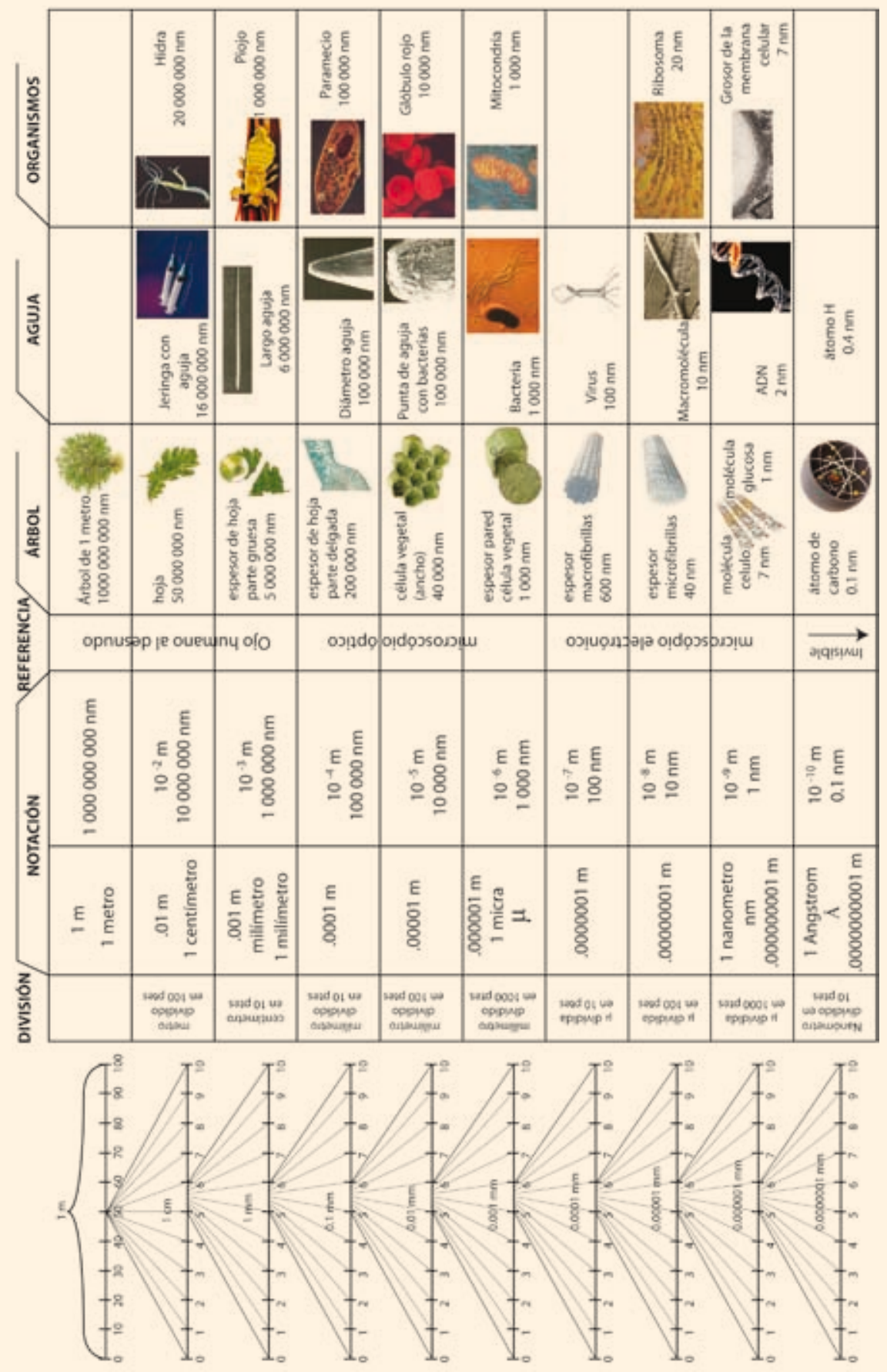

